\title{
Itemised deductions: a device to reduce tax evasion
}

\author{
Amedeo Piolatto* \\ Barcelona Economics Institute (IEB), University of Barcelona
}

28th August 2014

\begin{abstract}
With direct incentives and sanctions being the most common instruments to fight tax evasion, the theoretical literature has tended to overlook indirect schemes, such as itemised deductions, in which one agent's behaviour affects the likelihood that others will declare their revenue. Itemised deductions provide an incentive for consumers to declare their purchases. This induces a partial shift in the demand from the black market to the legal one, for consumers need a transaction receipt to enjoy the tax deduction. I show that it is possible to increase tax proceeds by choosing a suitable level of itemised deduction, and this, for any level of taxation. Indeed, the cost for the tax authority on the consumers' side is more than compensated for by the extra proceeds generated on the sellers' side.
\end{abstract}

JEL Classification: H00; H20; H26; H30

Keywords: Tax evasion, itemised deductions, substitute goods, duopoly.

Acknowledgements: Part of the research was conducted at the Universitat d'Alacant and at Tilburg University, I am grateful to both institutions. For their comments and support, I am indebted to the editor of GEER and the two anonymous referees, to Federico Boffa, Philippe De Donder, Peter Claeys, Pierre Pestieau, Miguel Sanchez Villalba, Domenico Siniscalco, Florian Schuett and seminars' participants at the universities of Alicante, Barcelona and Tilburg. Financial support from the Spanish Ministry of Science and Innovation (grant ECO2012-37131) is gratefully acknowledged.

\footnotetext{
${ }^{*}$ Barcelona Economics Institute, University of Barcelona, c/ T. C. Valenzuela, 1-11, 08034 Barcelona, Spain. E-mail: piolatto[at]ub.edu
} 


\section{Introduction}

Tax evasion is often associated with self-employment, and more specifically with partial evaders who are legally entitled to trade a good or service, but they don't declare all their transactions. However, full evaders are relatively common too. Full evaders are subjects that are not legally allowed to trade (either because they lack some legal authorisation, or because they trade an illegal good or service) and therefore they do not appear in the tax authority registry. Among others, this includes not-licensed accommodation and taxis, street sellers, tobacco smuggler, and drug sellers. The goods they trade tend to be (imperfect) substitutes of some legal ones with which they compete. Competition is distorted by taxes, and any unit sold on the black market represents a loss from the perspective of the tax authority, which would benefit from a shift in consumption from the black to the legal market. Technological advance (internet, smartphones, etc.) has significantly facilitated the provision of services from not legally registered providers. For instance, it is now easier to find underground substitutes for removal companies, taxis or B\&B.

The analysis of tax evasion in this context differs from the case of collaborative tax evasion in a crucial aspect. Under collaborative tax evasion, the seller and the buyer meet, and they can decide on the type of transaction to conduct. Under such circumstances, a bargain process may start, aimed at finding a price for the illegal transaction to be preferred by both agents. This is not possible when two substitute goods are sold by two different economic agents, each specialised in either market (legal or underground). Typical examples of this could be tobacco, drugs, and digital content goods (music, films, software): legal sellers (tobacco shops, authorised drugs shops, music and film stores) are under strict legal control and they are likely to only conduct legal transactions. Close substitutes to these goods are sold on the black market (tobacco and drugs smugglers, dvd street sellers, illegal stores on the web or on the deep web). Clearly, those sellers cannot declare their transactions. Hence, consumers choose beforehand the type of transaction. In this paper, I restrain my attention to the case of full evaders and disregard collaborative tax evasion.

Tax evasion is a major concern in most countries; however, owing to its nature, it is extremely hard to estimate. Among the best known attempts to quantify it, Franzoni (1999) and Slemrod (2007) focus on the United States. Single and cross-country studies conducted at different points in time suggest that the black economy in western countries may range between 5\% and 27\% of GDP (Buehn, 2012; Cowell, 1985; Feld and Schneider, 2010; Schneider, 2005). In the theoretical literature on tax evasion, the seminal work by Allingham and Sandmo (1972) is the first to consider tax evasion as a decision under risk. ${ }^{1}$

\footnotetext{
${ }^{1}$ See Alm (2012); Buehn and Schneider (2012) and Slemrod and Weber (2012) for an analysis of the limits
} 
The literature on tax evasion is devoted mainly to income taxation, ${ }^{2}$ and concentrates on how evasion can be deterred through detection and sanctions (Franzoni, 1999). ${ }^{3}$ Rational consumers decide whether or not to evade payment of their taxes based on a cost-benefit comparison. ${ }^{4}$ Despite the desire of tax authorities to fight tax evasion, ${ }^{5}$ the instruments available are limited to two types: reducing the benefits from evasion (e.g., lowering tax rates) and increasing its cost (e.g., imposing higher fines or implementing more sophisticated audit systems). However, auditing costs and agents' limited liability are major constraints on legislators policy space.

Here, I focus on an indirect mechanism: itemised deductions (also known as tax deductions or tax credits). Deductions allow consumers to reduce their tax base if they can certify expenditure on certain selected goods or services. To the best of my knowledge, this is the first paper dealing with itemised deductions when the legal and underground market are separate. However, my model is not a proper representation of the case of a self-employed who can bargain with the client and decide if they prefer to declare the sale or not (collaborative tax evasion). Gordon (1990) seminal paper proposes a model with one seller accepting both (not declared) cash payments and legal transactions, and offering a discount for cash payments. The author focuses on the price discrimination aspect, suggesting that the discount is offered to consumers with low willingness to pay, who are more willing to bear the risk of infringing the law. Anderberg et al. (2003) also consider collaborative tax evasion, adding search costs to operate in the black market. Neither of these articles studies itemised deductions within their framework. A brief overview of the most recent literature on collaborative tax evasion is available in Immordino and Russo (2014). This paper, to the best of my knowledge, is the first to analyse the impact of itemised deductions under collaborative tax evasion, although their main focus is on the impact of taxing cash. When the seller and the buyer can bargain, deductions may be less effective because the potential gain for the tax authority implies some room for negotiation. However, their results are similar in flavour to mine: the introduction of itemised deductions can induce an increase in tax proceeds. Under collaborative tax evasions,

to the empirical study of tax evasion. Refer to Andreoni et al. (1998); Slemrod and Yitzhaki (2002); Slemrod (2007); Franzoni (2009) for surveys of the rich literature, both theoretical and empirical, that followed Allingham and Sandmo (1972).

${ }^{2}$ Cremer and Gahvari (1993) and Marelli (1984) are notable exceptions.

${ }^{3}$ Little has been said about firms' tax evasion. Most literature has adapted to firms the standard model of agents' evasion. Bayer and Cowell (2009) show that the market/economy structure may affect firms behaviour.

${ }^{4}$ Evasion may also derive from the willingness to hide illegal activities: even under no taxation, the underground economy may still represent a positive share of GDP, because of illegal activities and agents willing to avoid regulation laws.

${ }^{5}$ In addition to fighting evasion to increase tax proceeds, notice that undeclared income is more likely to finance other illegal activities (Fortin et al., 2000). Hence, by controlling it, the authority also reduces other illicit activities. However, one line in the literature claims that, under specific circumstances, tax evasion may be welfare improving. For an analysis of the welfare consequences of fighting tax evasion, see Davidson et al. (2007) and section 7 of Cowell (1985). 
itemised deductions seem to be more effective when there are limits or costs to bargain, as in the case of agents heterogeneity and incomplete information.

I consider a market with two substitute goods, available one on the legal market and the other on the black market. I focus solely on the case in which sellers on the two markets are separate entities. Both consumers' wealth and declared profits are taxed at some, possibly different, exogenous tax rate. Itemised deductions allow consumers to reduce their tax base by declaring their purchases. ${ }^{6}$ Deductions are possible only for legal purchases, and this requires consumers to buy legally. ${ }^{7}$ I show that, in equilibrium, undeclared profits fall and total tax proceeds (net of the incentive for consumers) rise when consumers have incentives to declare their purchases.

The model I describe shows that the partial deductibility of expenditures serves as enough of an incentive for consumers to declare their purchases, while not affecting tax proceeds negatively. The reduction in the amount of taxes collected from consumers is less substantial than the increase in tax proceeds derived from the reduction in the evasion of the tax on profits. The itemised deduction that maximises tax proceeds is always positive, which means that, ceteris paribus, introducing deductions implies: a) that the public budget constraint is relaxed (higher tax proceeds and/or lower tax rates) and b) that the size of the black market shrinks.

Section 2 presents the model. The results of the model are analysed and commented on in section 3. The last section concludes. Appendix A proposes some extensions of the main model, while the proofs are relegated to appendix B.

\section{The model}

Here, I describe the main elements of the model: the representative consumer, the firms and, finally, the tax authority.

The representative consumer The consumption set of the representative agent includes the numeraire good $M$ and a consumption good, available both legally $(\mathrm{X})$ and illegally $(\mathrm{Y})$ : the sets $(x, p)$ and $(y, q)$ denote, respectively, the quantity and price on the legal and black markets.

For the consumer, $X$ and $Y$ are versions of the same good, and as such are substitutes. The degree of substitutability may range from perfect (e.g., a brand new, stolen CD) to very

\footnotetext{
${ }^{6}$ From a practical perspective, in the past such a mechanism would have entailed significant implementation costs. Nowadays, a chip card could easily register all legal transactions.

${ }^{7} \mathrm{~A}$ similar idea is implemented in France: the government partially subsidises the rent of the poorest citizens through the "Aide au Logement", whereby landlords are obliged to declare their rent income or to reduce the rent by the value of the subsidy.
} 
low (e.g., plagiarised software). The parameter $\sigma$ accounts for this.

I assume that the utility function $(U)$ of the representative consumer is the standard quasi-linear function for imperfect substitute goods, which leads to linear demand functions: ${ }^{8}$

$$
U(x, y, M)=\left(x-x^{2}\right)+\left(y-y^{2}\right)-2 \sigma x y+M
$$

where $\sigma \in(0,1)$ is the degree of substitutability between $X$ and $Y{ }^{9}$

The consumer's income $I$ is exogenous and $t$ is the rate of the tax levied on it. An itemised deduction is a per-unit reduction in the tax base granted after the purchase of the legal good. A deduction of $a$ is granted for any purchase exceeding the exogenous threshold $x_{0} \cdot{ }^{10} \mathrm{I}$ assume the threshold $x_{0}$ to equal the number of units purchased in equilibrium when itemised deductions are not allowed, i.e., $x_{0}=\left.x\right|_{a=0} \cdot{ }^{11}$ The consumer's problem can be written as:

$$
\max _{x, y, M} U(x, y, M) \quad \text { s.t. } p x+q y+M \leq I-t\left(I-a\left(x-x_{0}\right)\right)
$$

Solving the consumer's problem, the demand functions are:

$$
\begin{aligned}
& x=\frac{1-p+\sigma q-\sigma+a t}{2\left(1-\sigma^{2}\right)} \\
& y=\frac{1-q+\sigma p-\sigma-\sigma a t}{2\left(1-\sigma^{2}\right)} .
\end{aligned}
$$

The firms Here, I consider the simplest possible setting for the market, while appendix A considers some extensions. Assuming two sub-markets (a legal and illegal market), I consider a duopoly with one firm operating in each sub-market. This structure might apply, for example, to the case of music, sold legally by a record label, on the one hand, and illegally by an organised cartel, on the other. I assume the game to be sequential, with the legal firm choosing first. As a simplifying assumption, I consider the case of null marginal cost. ${ }^{12}$ By construction, only the legal firm pays the tax $T$ on its profits.

\footnotetext{
${ }^{8}$ Boone and Pottersz (2006) analyse the properties of this utility function for the case of $n$ different goods.

${ }^{9}$ The value of $\sigma$ depends on the real characteristics of the goods, and hence on their substitutability. Note that for $\sigma=1$, the utility function can be reduced to the case of perfect substitute goods. For the other parameter values, the goods remain substitutes (i.e., the partial derivative of the demand for one good with respect to the consumption of the other good is negative), although not perfect.

10 The threshold $x_{0}$ is meant to reduce the cost for the government of implementing this policy. An excessively high threshold decreases the attractiveness of deductions, while an excessively low threshold implies a larger opportunity cost of implementing the policy. It is beyond the scope of this study to compute the optimal level of the threshold. The choice of a per-unit deduction instead of an ad valorem one is both for mathematical convenience and because solving the model with an ad valorem tax provides very similar results but it generates inflation in prices which introduces a noise when interpreting the results.

11 This paper does not compute the optimal level of $x_{0}$ : the choice of $x_{0}=\left.x\right|_{a=0}$ is for mathematical convenience. This choice make it look somehow endogenous. Results are robust to a change in $x_{0}$, as long as it is not too large and agents consider it exogenous.

12 The organisation of the market depends heavily on the type of good considered. The model is robust to certain adjustments so as to fit different markets: appendix A.1 solves the model for the case of simultaneous competition, while appendix A.3 solves for the case of $c>0$.
} 
The followers maximisation problem, given the demand function in (4), is

$$
\max _{y, q} \quad q y \quad \text { s.t. } \quad y=\frac{1-q+\sigma p-\sigma-\sigma a t}{2\left(1-\sigma^{2}\right)} .
$$

Hence, the price on the black market is $q=\frac{1-(1+a t-p) \sigma}{2}$, and the leader's maximisation problem is:

$$
\begin{aligned}
\max _{x, p}(1-T) p x \quad \text { s.t. } \quad x & =\frac{1-p+\sigma q-\sigma+a t}{2\left(1-\sigma^{2}\right)} \\
q & =\frac{1-(1+a t-p) \sigma}{2} .
\end{aligned}
$$

Solving the problem, we obtain:

$$
\begin{aligned}
& p=\frac{1+a t}{2}-\frac{\sigma}{2\left(2-\sigma^{2}\right)} \\
& x=\frac{\left(2-\sigma^{2}\right)(1+a t)-\sigma}{8\left(1-\sigma^{2}\right)} \\
& q=\frac{1}{2}\left(1-\frac{(1+a t) \sigma}{2}-\frac{\sigma^{2}}{2\left(2-\sigma^{2}\right)}\right) \\
& y=\frac{1}{4\left(1-\sigma^{2}\right)}\left(1-\frac{(1+a t) \sigma}{2}-\frac{\sigma^{2}}{2\left(2-\sigma^{2}\right)}\right)=\frac{q}{2\left(1-\sigma^{2}\right)} .
\end{aligned}
$$

The tax authority The tax authority maximises total tax proceeds (TP), which are given by the sum of proceeds from income and profits taxes: $T P(a)=T p x+t\left(I-a\left(x-x_{0}\right)\right.$.

Here, my focus is on itemised deductions. I assume that both tax rates are exogenous (that is, the central authority has already chosen the optimal rates) and I focus on the optimal level of deduction. The authority chooses $a$, that is, the reduction in the tax base to which the consumer is entitled for each unit of $x$ purchased above the threshold $x_{0}$. From the definition of $x_{0}=\left.x\right|_{a=0}$ and equation (8), we have that $x_{0}=\frac{2-\sigma^{2}-\sigma}{8\left(1-\sigma^{2}\right)}$. The optimal level $a$ of deduction is defined as that which maximises tax proceeds, ${ }^{13}$ and which solves the following problem:

$$
\begin{aligned}
\max _{a} T p x+t\left(I-a\left(x-x_{0}\right)\right) \quad \text { s.t. } p & =\frac{1+a t}{2}-\frac{\sigma}{2\left(2-\sigma^{2}\right)} \\
x & =\frac{\left(2-\sigma^{2}\right)(1+a t)-\sigma}{8\left(1-\sigma^{2}\right)} .
\end{aligned}
$$

from which we obtain:

$$
a=\frac{T}{t} \frac{2-\sigma^{2}-\sigma}{(2-T)\left(2-\sigma^{2}\right)}
$$

\footnotetext{
13 Clearly, the objective function of the authority may be different: e.g., minimising the black market. In that case, the model could be adapted in accordance with the central authoritys main objective.
} 
By replacing the equilibrium value of $a$, to compute the quantities and prices under the itemised deduction regime:

$$
\begin{aligned}
& p=\frac{2-\sigma-\sigma^{2}}{(2-T)\left(2-\sigma^{2}\right)} \\
& x=\frac{2+\sigma}{4(2-T)(1+\sigma)} \\
& q=\frac{(1-\sigma)(4-2 T(1+\sigma)+(2-\sigma) \sigma)}{2(2-T)\left(2-\sigma^{2}\right)} \\
& y=\frac{q}{2\left(1-\sigma^{2}\right)} .
\end{aligned}
$$

\section{Analysis and robustness of the results}

I am now in a position to analyse the results obtained from the previous equations and to draw my conclusions.

Proposition 1. For both goods, all equilibrium prices and quantities are positive, both before the introduction of the itemised deductions and when the optimal deduction is applied. Were a larger than optimal deduction to be introduced, however, the size of the illegal market could be further reduced, and might even disappear if the two goods were highly substitutable (i.e., $\sigma$ large).

Corollary. Equations (53) and (54) in the appendix describe, for each good, the change in consumption following a marginal change in the itemised deduction. As expected, consumption of the legal good increases in the level of itemised deductions, while consumption of y decreases. Equations (55) to (62) compute the way in which consumption reacts to a change in the model's parameters, both for a generic level of deductions and when the optimal deduction is introduced.

Proposition 1 guarantees that, at equilibrium, the solution is interior, and a positive quantity of both goods is consumed. In other words, it is not optimal to introduce a deduction of magnitude such that the consumption of the illegal good drops to zero, if the tax authority is only maximising tax proceeds. The reason for this is that it would be too costly to allow for a deduction of such magnitude. It should be noted, however, that out of equilibrium (that is, for a generic level of deductions), $y$ may drop to zero. Because the optimal deduction equation (12) - is clearly decreasing in $\sigma$, the deduction that allows to eliminate tax evasion depends on the degree of substitutability of the two goods. The reason for this is that when goods are poorly substitutable, it becomes more expensive to induce consumers to move from the illegal to the legal product. We obtain a corner solution with no consumption of 
the illegal good when $a t \geq \frac{(2-\sigma)\left(2-\sigma^{2}\right)-\sigma^{2}}{\sigma\left(2-\sigma^{2}\right)}$ : the equilibrium is given by $(q, y)=(0,0)$ and $(p, x)=\left(\frac{1+a t}{2}, \frac{1+a t}{4}\right)$.

The impact on consumption of itemised deductions - equations (53) and (54) - is as expected: they increase the consumption of the legal good and are detrimental to the consumption of the illegal good. The magnitude of the effect depends on income tax $t$, as deductions operate as a reduction in the income tax due. The profit tax does not affect the equilibrium quantities directly; hence, from equations (8) and (10) one obtains that $\frac{\partial x}{\partial T}=\frac{\partial y}{\partial T}=0$. However, $T$ has an impact on quantities through the equilibrium deduction. Therefore, from equations (14) and (16), an increase in the profit tax has a positive effect on the consumption of the legal good $\left(\frac{\partial x}{\partial T}>0\right)$ and a negative effect on the consumption of the illegal good $\left(\frac{\partial y}{\partial T}<0\right)$. Finally, the impact of $\sigma$ on $x$ is negative when deductions are not used and also when the optimal deduction is applied; however, for other levels of deduction it is impossible to sign the impact of $\sigma$ on $x$. In the case of $y$, it is never possible to sign the impact of $\sigma$, which depends on the relative size of the model's parameters.

Given its policy implications, it is important to study the characteristics of $a$ and the effect of the various parameters on it. Proposition 2 and its corollary do just that.

Proposition 2. The optimal itemised deduction, defined by equation (12), is always positive. Corollary. Equations (17) to (19) describe the change in the optimal itemised deduction after a marginal change in the model parameters $\sigma, T$ and $t$.

$$
\begin{aligned}
\frac{\partial a}{\partial T} & =\frac{2 a}{T(2-T)}>0 \\
\frac{\partial a}{\partial t} & =-\frac{a}{t}<0 \\
\frac{\partial a}{\partial \sigma} & =-\frac{T\left(2+\sigma^{2}\right)}{t(2-T)\left(2-\sigma^{2}\right)^{2}}<0
\end{aligned}
$$

Proposition 2 states an important result, with unambiguous policy implications. It says that, regardless of the level of taxes and of $\sigma$, the tax authority will always find it profitable to introduce itemised deductions. The positive relation with $T$ and the negative relation with $t$ reflect the benefits and costs of deductions. Indeed, the tax rate on profits is positively correlated with the benefits of deductions: for a larger $T$, increasing the size of the legal market becomes more profitable. As soon as the marginal benefit of deductions increases, its equilibrium level adjusts upwards. The opposite reasoning applies for a larger income tax rate, since a larger $t$ means a larger marginal cost of implementing a deduction policy.

The impact of $\sigma$ on most variables is ambiguous. Indeed, it is indeterminate for quantities and profits on the legal market. However, equation (19) shows a clear negative correlation 
between optimal deductions $a$ and the degree of substitutability $\sigma$. This is because when goods are highly substitutable ( $\sigma$ large), a small deduction and the consequent change in relative prices is enough to generate a relatively large shift in consumption from the illegal to the legal market. Conversely, for small levels of $\sigma$, a large deduction is necessary to shift consumption. The fact that the policy is more effective implies that a low level of evasion is achieved with little deductions. Because the marginal benefit from shifting consumption is decreasing, and large $\sigma$ speed the shifting process, the marginal benefit of increasing deductions is lower.

Some of the results in propositions 1 and 2 can be generalised, by replacing the utility function in equation (1) with a generic, well-behaved, function $U$. Then, it is possible to rewrite the tax authority problem in equation (11) as

$$
\max _{a} T \pi_{x}+t\left(I-a\left(x-x_{0}\right)\right)
$$

where $\pi_{x}$ is the profit of the legal firm. The first derivative is $T \frac{\partial \pi_{x}}{\partial a}+t\left(\left(x-x_{0}\right)+a \frac{\partial x}{\partial a}\right)$. It is immediate to notice that at least at $a=0$, the derivative is positive, since the second term would disappear under the assumption that $x_{0}=\left.x\right|_{a=0}$. Furthermore, using the implicit function theorem, we can notice that $\frac{\partial a^{*}}{\partial T}>0$ and $\frac{\partial a^{*}}{\partial t}<0$.

Notice that the results (both in the baseline model and in its generalisation) depends on the function being behaved, meaning that we are focusing on the interesting case of interior solutions for the consumption both on the legal and the illegal market. In the baseline model, this is ensured by the choice of the utility function that guarantees interior solutions. If we fail to have either market, then the model looses its interest. However, it may be interesting to notice that the structure of the deduction (that applies only for units consumed above a threshold) has an effect of consumption on the legal market that is unrelated to the existence of a black market. Indeed, the deduction is offered only for "the marginal units" for which, under standard assumptions, the willingness to pay is lower. This means that such itemised deduction increase the efficiency in a market characterised by some market power in a way similar to the one of price discrimination, because the seller can maintain the same price and still sell some additional units that are subsidised.

The optimal value of $a$ is computed for a generic tax rate, including the equilibrium tax rate. One can only speculate on how the optimal tax rate is affected by the introduction of deductions. Following the intuition in Cremer and Gahvari (1993), goods should be taxed less when the evasion elasticity to taxes is larger. Itemised deductions reduce the incentive to evade, hence under a constant public budget constraint and several taxed goods, I would expect the optimal relative tax rates to adjust to account for the impact of the deduction (i.e., the optimal tax rate would increase for goods for which the deduction is more effective, and decrease for the others). 


\section{Conclusion}

This study has examined the effectiveness of itemised deductions as a device for reducing tax evasion. Agents consume a good that they purchase either on the legal or the black market (or both) and they pay a tax on their exogenous income. Consumers perceive the two goods as substitutes. Two firms (one legal, the other illegal) are active. ${ }^{14}$ Only the legal firm pays a tax on its profits. The tax authority chooses the level of itemised deductions that maximise tax proceeds.

Itemised deductions generate both costs and benefits for the tax authority: income-tax proceeds decrease, but deductions generate a shift in consumption from the illegal to the legal market, which increases the legal firm's profits and, hence, extra proceeds from the profit tax are collected. I have computed the deduction that maximises tax proceeds.

I show that the optimal deduction is positive for any combination of parameters, indicating that itemised deductions are always beneficial (in terms of tax proceeds). The cost of deductions (i.e., the fall in income tax proceeds) is always more than compensated for by an increase in the legal firm's profits and the subsequent increase in the proceeds from the profit $\operatorname{tax}$.

In my model, I only consider the direct benefit of reducing evasion; however, Galbiati and Zanella (2012) document a tax evasion social multiplier, which suggests that reducing the tax evasion of one economic agent induces other agents to comply too. Furthermore, deductions are shown to be detrimental to the profit levels of the underground sector; and, as it seems likely that the underground economy finances other criminal activities (Fortin et al., 2000), itemised deductions may also be effective in reducing criminal activities. ${ }^{15}$

Appendix A.2 shows that if itemised deductions are combined with an audit-and-fine program, the two may co-exist in equilibrium. Indeed, the conducting of audits aimed at discouraging evasion partially reduces the effectiveness of deductions, but the cost of auditing and limited liability make auditing an imperfect instrument. Depending on the assumptions made in relation to the cost of auditing and the fine imposed, it may be profitable, in equilibrium, for the tax authority to combine audit and itemised deductions.

Itemised deductions tend to induce a redistribution of income among citizens, but they do not increase efficiency per se. As a matter of fact, consumers and the legal firm tend to benefit from deductions, but the illegal firm looses from it. Under standard assumptions (no side transfers to compensate the illegal firm), we cannot have a Pareto improvement. However,

\footnotetext{
14 The main model considers sequential competition, with the legal firm being the leader. Following the insight of Bayer and Cowell (2009), the market structure may affect our results. Appendix A.1 strengthen the previous results by analysing the simultaneous case, and showing that results are qualitatively the same.

15 For this reason, and depending on the social welfare function, the government may prefer a higher than optimal level of deduction, which would reduce tax proceeds but bring about a reduction in crime.
} 
if tax proceeds are used to provide public goods, it would be possible to observe a Pareto Improvement if the benefits from public goods are enough to compensate the owners of the illegal firm. The welfare implications of the model are left for future research. To compute the change in total welfare, some assumptions are needed on how the additional tax proceeds are used (redistribution or public goods provision or reduction of distortive taxes) and on the relative weight of the illegal firm in the welfare function. ${ }^{16}$

An interesting application of the results of this model would be to estimate the long-term effects of setting deductions above the optimal level on the black economy and on criminal activity. Indeed, the losses on one underground market could generate spillovers on other (financially connected) illegal markets. The tax authority might be willing to internalise these additional effects.

In my model, the two firms are separate entities. It may be possible that the two firms are connected, as in the case of a business that partially evades taxes (collaborative tax evasion). In such a case, the introduction of deductions reduces the firms bargaining power and hence its profit. However, in this framework the firm is legal and hence it may have some lobby power. It would therefore be interesting, from a political economy viewpoint, to study the political viability of a reform introducing deductions that were dependent on the composition of economic activities (differentiating between businesses that may or may not hide part of their activity).

16 Bear in mind that as a result of itemised deductions, tax proceeds shift from income tax to profit taxes, where the former tends to be distortive and the latter not. 


\section{Appendix A Other market configurations}

Here, I present the main results under different market configurations. Specifically, subsection A.1 considers the case of a duopoly in which the firms decide simultaneously. Subsection A.2 analyses the case in which the tax authority combines deduction with an audit-and-fine program, while subsection A.3 extends the main analysis to the case of a positive marginal cost of production.

\section{A.1 Simultaneous competition}

Here, I solve the model for the case of simultaneous competition. The behaviour of the representative agent remains the same, as does the problem faced by the firm operating on the black market (previously, the follower). Hence, the reaction function of this illegal firm remains $q=\frac{1-(1+a t-p) \sigma}{2}$.

The problem of the legal function is now

$$
\max _{x, p}(1-T) p x \quad \text { s.t. } \quad x=\frac{(1+a t-\sigma)+\sigma q-p}{2\left(1-\sigma^{2}\right)}
$$

From the first order condition, we obtain that $p=\frac{(1+a t-\sigma)+\sigma q}{2}$. Solving the resulting system of equations, the equilibrium is:

$$
\begin{aligned}
& p=\frac{(1+a t)\left(2-\sigma^{2}\right)-\sigma}{4-\sigma^{2}} \\
& q=\frac{2-(1+a t+\sigma) \sigma}{4-\sigma^{2}} \\
& x=\frac{(1+a t)\left(2-\sigma^{2}\right)-\sigma}{2\left(4-\sigma^{2}\right)\left(1-\sigma^{2}\right)} \\
& y=\frac{q}{2\left(1-\sigma^{2}\right)} .
\end{aligned}
$$

It is immediately apparent that $p>0$ and $x>0$. In the case of $y$ and $q$, they are always positive when $a t=0$, i.e., under the no-deduction regime, some tax evasion is always observed. For sufficiently large at $\left(a t>\frac{2-(1+\sigma) \sigma}{\sigma}\right), y$ may drop to zero. When competition is simultaneous, $x_{0}=\left.x\right|_{a=0}=\frac{2-\sigma^{2}-\sigma}{2\left(4-\sigma^{2}\right)\left(1-\sigma^{2}\right)}$.

The problem of the authority becomes

$$
\begin{aligned}
\max _{a} T p x+t\left(I-a\left(x-x_{0}\right) \quad \text { s.t. } p\right. & =\frac{(1+a t)\left(2-\sigma^{2}\right)-\sigma}{4-\sigma^{2}} \\
x & =\frac{(1+a t)\left(2-\sigma^{2}\right)-\sigma}{2\left(4-\sigma^{2}\right)\left(1-\sigma^{2}\right)} .
\end{aligned}
$$

From the first order condition, the optimal itemised deduction is:

$$
a=\frac{T}{t} \frac{2-\sigma^{2}-\sigma}{2(2-T)-\sigma^{2}(1-T)} .
$$


We can then study the behaviour of $a$ when changing the value of the parameters.

$$
\begin{aligned}
\frac{\partial a}{\partial T} & =\frac{1}{t} \frac{(2-\sigma)(1-\sigma)(2+\sigma)^{2}}{\left(2(2-T)-\sigma^{2}(1-T)\right)^{2}}>0 \\
\frac{\partial a}{\partial t} & =-\frac{T}{t} \frac{\left(2-\sigma-\sigma^{2}\right)}{\left(2(2-T)-\sigma^{2}(1-T)\right)^{2}}<0 \\
\frac{\partial a}{\partial \sigma} & =-\frac{T}{t} \frac{2(2-T)+\sigma^{2}(1-T)+4 \sigma}{\left(2(2-T)-\sigma^{2}(1-T)\right)^{2}}<0
\end{aligned}
$$

Finally, when the optimal itemised deduction is applied, the equilibrium is

$$
\begin{aligned}
& p=\frac{(1-\sigma)(2+\sigma)}{\left(2(2-T)-\sigma^{2}(1-T)\right)}>0 \\
& q=\frac{(1-\sigma)(2-T+(1-T) \sigma)}{\left(2(2-T)-\sigma^{2}(1-T)\right)}>0 \\
& x=\frac{2+\sigma}{2(1+\sigma)\left(2(2-T)-\sigma^{2}(1-T)\right)}>0 \\
& y=\frac{q}{2\left(1-\sigma^{2}\right)}>0 .
\end{aligned}
$$

\section{A.2 Deductions and auditing}

In the core model, I do not explicitly consider the possibility of deterring evasion by conducting audits and imposing fines, a common technique and one that has been widely studied in the literature. In this subsection, I study the main interactions between auditing and the optimal deduction.

A fine affects the illegal firms expected profits, but, unless it results in the firms exit from the market, it does not affect its decisions regarding quantities and prices. Audits and fines can be modelled in many ways; however, to guarantee a closed-form solution, without having to make any assumptions about functional forms, I focus on fines that do not depend on the illegal firms profits (i.e., a lump-sum fine). Yet, it should be stressed that a fine proportional to the tax evaded is more common. Here, I solve first for a generic function that includes all possible types of fine, and then show the closed-form solution for the aforementioned case.

Define by $\alpha$ the probability of being audited, and by $F(\alpha, q y)$ the generic fine function (that is, all payments due in case of audit), and by $\Delta(\alpha)$ the cost of auditing, assumed to be increasing and convex in $\alpha$. Taking into account auditing (and fining), the maximisation problem of the black market firm becomes

$$
\max _{y, q} q y-F(\alpha, q y) \quad \text { s.t. } y=\frac{1-q+\sigma p-\sigma-\sigma a t}{2\left(1-\sigma^{2}\right)} .
$$

The value of $\alpha$ affects profits but does not impact the solution of the problem, which remains 
the same as in equations (9) and (10). The maximisation problem of the authority becomes

$$
\begin{aligned}
\max _{a, \alpha} & T p x+t\left(I-a\left(x-x_{0}\right)\right)+F(\alpha, q y)-\Delta(\alpha) \\
\text { s.t. } & p=\frac{1+a t}{2}-\frac{\sigma}{2\left(2-\sigma^{2}\right)} \\
q & =\frac{1}{2}\left(1-\frac{(1+a t) \sigma}{2}-\frac{\sigma^{2}}{2\left(2-\sigma^{2}\right)}\right) \\
x & =\frac{\left(2-\sigma^{2}\right)(1+a t)-\sigma}{8\left(1-\sigma^{2}\right)} \\
y & =\frac{q}{2\left(1-\sigma^{2}\right)} .
\end{aligned}
$$

The solution to this problem is given by the following system of equations:

$$
\begin{cases}a & =\frac{T}{t} \frac{2-\sigma^{2}-\sigma}{(2-T)\left(2-\sigma^{2}\right)}+\frac{8\left(1-\sigma^{2}\right)}{(2-T)\left(2-\sigma^{2}\right) t^{2}} \frac{\partial F(\alpha, q y)}{\partial a} \\ \frac{\partial \Delta(\alpha)}{\partial \alpha} & =\frac{\partial F(\alpha, q y)}{\partial \alpha}\end{cases}
$$

Assuming the fine to be a lump sum $\bar{F}$, orthogonal to profits, so that $F(\alpha, q y)=\alpha \bar{F}$, then $\frac{\partial F(\alpha, q y)}{\partial a}=0$, and $\frac{\partial F(\alpha, q y)}{\partial \alpha}=\bar{F}$, the solution to the agency problem in equation (36) becomes

$$
\begin{cases}a & =\frac{T}{t} \frac{2-\sigma^{2}-\sigma}{(2-T)\left(2-\sigma^{2}\right)}>0 \\ \frac{\partial \Delta(\alpha)}{\partial \alpha} & =\bar{F}>0\end{cases}
$$

It is immediately apparent that the optimal value of $a$ is not affected by the audit-and-fine policy, and that in equilibrium, both $a$ and $\alpha$ are positive. However, in the more general case, it may be optimal not to have itemised deductions. Indeed, an inspection of the system of equations (37) reveals that the optimal $a$ includes a positive term, to which should be added a negative term, whose magnitude depends on $\frac{\partial F(\alpha, q y)}{\partial a}$ and $\frac{\partial \Delta(\alpha)}{\partial \alpha}$. Even if we assume a specific functional form for $F(\alpha, q y)$, the sign of the optimal $a$ depends on the cost of audit and on $\sigma$.

\section{A.3 Positive marginal cost}

In this section, I solve the model for the case of sequential competition and positive marginal cost $c>0$. The consumer's demand functions are unaffected. The follower's maximisation problems, given the demand function in (4), can be expressed as

$$
\begin{aligned}
\max _{y, q} & (q-c) y \\
\text { s.t. } & y=\frac{1-q+\sigma p-\sigma-\sigma a t}{2\left(1-\sigma^{2}\right)},
\end{aligned}
$$


hence, the price on the black market is $q=\frac{1-(1+a t-p) \sigma+c}{2}$. The leader's maximisation problem is:

$$
\begin{aligned}
\max _{x, p} & (1-T)(p-c) x \\
\text { s.t. } & x=\frac{1-p+\sigma q-\sigma+a t}{2\left(1-\sigma^{2}\right)} \\
& q=\frac{1-(1+a t-p) \sigma+c}{2}
\end{aligned}
$$

from which we obtain

$$
\begin{aligned}
& p=\frac{1+a t+c}{2}-\frac{\sigma(1-c)}{2\left(2-\sigma^{2}\right)} \\
& x=\frac{\left(2-\sigma^{2}\right)(1+a t-c)-\sigma(1-c)}{8\left(1-\sigma^{2}\right)} \\
& q=\frac{1}{2}\left(1-\frac{(1+a t) \sigma}{2}+\frac{(2+\sigma) c}{2}-\frac{(1-c) \sigma^{2}}{2\left(2-\sigma^{2}\right)}\right) \\
& y=\frac{1}{4\left(1-\sigma^{2}\right)}\left(1-\frac{(1+a t) \sigma}{2}-\frac{(2-\sigma) c}{2}-\frac{(1-c) \sigma^{2}}{2\left(2-\sigma^{2}\right)}\right) .
\end{aligned}
$$

The tax authority solves the following problem:

$$
\begin{array}{rl}
\max _{a} & T(p-c) x+t\left(I-a\left(x-x_{0}\right)\right) \\
\text { s.t. } & p=\frac{1+a t+c}{2}-\frac{\sigma(1-c)}{2\left(2-\sigma^{2}\right)} \\
& x=\frac{\left(2-\sigma^{2}\right)(1+a t-c)-\sigma(1-c)}{8\left(1-\sigma^{2}\right)},
\end{array}
$$

from which the optimal deduction follows:

$$
a=\frac{T}{t} \frac{(1-c)\left(2-\sigma^{2}-\sigma\right)}{(2-T)\left(2-\sigma^{2}\right)}
$$

Comparing this result with that obtained for $c=0$, it is immediately apparent that the sole difference originates from the multiplicative term $(1-c)$. The comparative statics on $a$ maintains the same sign:

$$
\begin{aligned}
\frac{\partial a}{\partial T} & =\frac{2 a}{T(2-T)}>0 \\
\frac{\partial a}{\partial t} & =-\frac{a}{t}<0 \\
\frac{\partial a}{\partial \sigma} & =-\frac{T\left(2+\sigma^{2}\right)(1-c)}{t(2-T)\left(2-\sigma^{2}\right)^{2}}<0 \\
\frac{\partial a}{\partial c} & =-\frac{T\left(2-\sigma^{2}-\sigma\right)}{t(2-T)^{2}\left(2-\sigma^{2}\right)^{2}}<0
\end{aligned}
$$


but now we also have the, clearly negative, derivative of $a$ with respect to $c$. Thus, as costs increase, profits fall as do the proceeds from the profit tax. As such, it is less profitable to provide incentives to consume the legal good.

Finally, replacing the optimal value of $a$ in equations (42) and (44), we obtain:

$$
\begin{aligned}
& x=\frac{(1-c)(2+\sigma)}{4(2-T)(1+\sigma)}>0 \\
& y=\frac{(1-c)(4+(2-\sigma) \sigma-2 T(1+\sigma))}{4(2-T)(1+\sigma)\left(2-\sigma^{2}\right)}>0 .
\end{aligned}
$$

Here, again, when computing the equilibrium on the introduction of the optimal deduction, it is clear that the quantity exchanged on the black market remains positive. In other words, itemised deductions help reduce the level of consumption of the illegal product, but when the tax authority maximises tax proceeds, it is optimal to propose a deduction that does not mean all consumption becomes legal.

\section{Appendix B Proofs}

Proof of Proposition 1. First, consider prices and quantities for a generic level of itemised deductions, i.e., equations (7) to (10). It is immediately apparent that the condition that must be satisfied for $p$ and $x$ to be positive is $\left(2-\sigma^{2}\right)(1+a t)-\sigma>0$, which is equivalent to $\left(1-\sigma^{2}\right)(1+a t)+(1+a t-\sigma)>0$. This condition is always verified, as $\sigma<1$. The condition that must be satisfied for $q$ and $y$ to be positive requires $2\left(2-\sigma^{2}\right)>\left(2-\sigma^{2}\right)(1+a t) \sigma+\sigma^{2}$. When considering the no deductions case $(a t=0)$, the condition reduces to $\left(2-\sigma^{2}\right)(1-\sigma)+2(1-$ $\left.\sigma^{2}\right)>0$, which is clearly always verified. By contrast, if itemised deductions are introduced, we obtain the condition at $<\frac{(2-\sigma)\left(2-\sigma^{2}\right)-\sigma^{2}}{\sigma\left(2-\sigma^{2}\right)}$ that guarantees a positive consumption of illegal goods.

The following equations describe the change in consumption due to a marginal change in the value of the parameters.

$$
\begin{aligned}
\frac{\partial x}{\partial a t} & =\frac{\left(2-\sigma^{2}\right)}{8\left(1-\sigma^{2}\right)}>0 \\
\frac{\partial y}{\partial a t} & =-\frac{\sigma}{8\left(1-\sigma^{2}\right)}<0 \\
\frac{\partial x}{\partial T} & =0 \\
\frac{\partial y}{\partial T} & =0 \\
\frac{\partial x}{\partial \sigma} & =\frac{2 \sigma(1+a t)-1-\sigma^{2}}{8\left(1-\sigma^{2}\right)^{2}} \\
\frac{\partial y}{\partial \sigma} & =\frac{1}{8}\left(\frac{4 \sigma}{\left(2-\sigma^{2}\right)^{2}}-\frac{\left(1+\sigma^{2}\right) a t+(1-\sigma)^{2}}{\left(1-\sigma^{2}\right)^{2}}\right)
\end{aligned}
$$


Moving to the equilibrium prices and quantities when the optimal deduction is introduced - equations (13) to (16) - it is immediately apparent that all values are positive. The following equations describe the change in consumption due to a marginal change in the value of the parameters.

$$
\begin{aligned}
\frac{\partial x}{\partial T} & =\frac{2+\sigma}{4(2-T)^{2}(1+\sigma)}>0 \\
\frac{\partial y}{\partial T} & =-\frac{\sigma(2+\sigma)}{4(2-T)^{2}(1+\sigma)\left(2-\sigma^{2}\right)}<0 \\
\frac{\partial x}{\partial \sigma} & =-\frac{1}{4(2-T)(1+\sigma)^{2}}<0 \\
\frac{\partial y}{\partial \sigma} & =-\frac{1}{4(2-T)}\left(\frac{1}{(1+\sigma)^{2}}-4 \frac{(1-T) \sigma}{\left(2-\sigma^{2}\right)^{2}}\right)
\end{aligned}
$$

Proof of Proposition 2. The optimal deduction is $a=\frac{T}{t} \frac{2-\sigma^{2}-\sigma}{(2-T)\left(2-\sigma^{2}\right)}$. To study the sign, one can focus on the sign of $2-\sigma^{2}-\sigma=\left(1-\sigma^{2}\right)+(1-\sigma)$. It is immediately apparent that both terms are positive. 


\section{References}

Allingham, M. G., Sandmo, A., 1972. Income Tax Evasion: A Theoretical Analysis. Journal of Public Economics 1, 323-328.

Alm, J., 2012. Measuring, explaining, and controlling tax evasion: lesson from theory, experiments, and field studies. International Tax and Public Finance 19, 54-77.

Anderberg, D., Balestrino, A., Galmarini, U., 2003. Search and taxation in a model of underground economic activities. Economic Inquiry 41 (4), 647-659.

Andreoni, J., Erard, B., Feinstein, J., 1998. Tax Compliance. Journal of Economic Literature $36,818-860$.

Bayer, R., Cowell, F., 2009. Tax compliance and firms' strategic interdependence. Journal of Public Economics 93 (11-12), 1131 - 1143.

Boone, J., Pottersz, J., 2006. Transparency and prices with imperfect substitutes. Economic letters $93,398-404$.

Buehn, A., 2012. The shadow economy in german regions: An empirical assessment. German Economic Review 13, 275-290.

Buehn, A., Schneider, F., 2012. Shadow economies around the world: novel insights, accepted knowledge, and new estimates. International Tax and Public Finance 19, 139-171.

Cowell, F. A., 1985. The Economic Analysis of Tax Evasion. Bulletin of Economic Research $37,163-93$.

Cremer, H., Gahvari, F., 1993. Tax evasion and optimal commodity taxation. Journal of Public Economics 50, 261-275.

Davidson, C., Martin, L., Wilson, J. D., 2007. Efficient black markets? Journal of Public Economics 91, 1575-1590.

Feld, L. P., Schneider, F., 2010. Survey on the shadow economy and undeclared earnings in oecd countries. German Economic Review 11, 109-149.

Fortin, B., Lacroix, G., Montmarquette, C., 2000. Are Underground Workers More Likely to be Underground Consumers? Economic Journal 110, 838-60.

Franzoni, L. A., 1999. Tax evasion and tax compliance. Encyclopedia of Law and Economics vol. 4 , pp. 51-94. 
Franzoni, L. A., 2009. Tax evasion and tax avoidance. In: Garoupa, N. (Ed.), Criminal Law And Economics. Edward Elgar, pp. 290-319.

Galbiati, R., Zanella, G., 2012. The tax evasion social multiplier: Evidence from italy. Journal of Public Economics 96, 485-494.

Gordon, J. P. F., 1990. Evading taxes by selling for cash. Oxford Economic Papers 42 (1), pp. $244-255$.

Immordino, G., Russo, F. F., 2014. Taxing cash to fight collaborative tax evasion? CSEF working paper 351 .

Marelli, M., 1984. On indirect tax evasion. Journal of Public Economics 25, 181-196.

Schneider, F., 2005. Shadow economies around the world: what do we really know? Journal of Political Economy 23, 598-642.

Slemrod, J., Winter 2007. Cheating ourselves: The economics of tax evasion. Journal of Economic Perspectives 21, 25-48.

Slemrod, J., Weber, C., 2012. Evidence of the invisible: Toward a credibility revolution in the empirical analysis of tax evasion and the informal economy. International Tax and Public Finance 19, 25-53.

Slemrod, J., Yitzhaki, S., 2002. Tax avoidance, evasion, and administration. In: Auerbach, A. J., Feldstein, M. (Eds.), Handbook of Public Economics. Vol. 3 of Handbook of Public Economics. Elsevier, Ch. 22, pp. 1423-1470. 